\title{
The role of physical and psychological factors in occupational low back pain: a prospective cohort study
}

Anne-Marie Feyer, Peter Herbison, Ann M Williamson, Indira de Silva, John Mandryk, Leigh Hendrie, Max C G Hely

Department of Preventive and Social Medicine, University of Otago, PO Box 913, Dunedin, New Zealand A-M Feyer

P Herbison

School of Psychology, University of New South Wales, Sydney, NSW 2050, Australia A M Williamson

Data Analysis and Research Unit, WorkCover, GPO Box 5364, Sydney, NSW 2001, Australia I de Silva

National Occupational Health and Safety Commission, GPO Box 58, Sydney, NSW 2001, Australia

$\mathrm{J}$ Mandryk

L Hendrie

Department of Human Factors and

Ergonomics, National Safety Council of Australia, PO Box 708, Newtown, NSW 2042, Australia

M C G Hely

Correspondence to: Associate Professor Anne-Marie Feyer, Department of Preventive and Social Medicine,

University of Otago, PO Box 913, Dunedin, New Zealand email

afeyer@gandalf.otago.ac.nz

Accepted 16 September 1999

\begin{abstract}
Objective-To examine risk factors for onset of low back pain (LBP) in healthcare workers.

Methods-Nursing students, during their 3 year training period, and 1 year after training were studied in a prospective cohort study, with repeated self reported measurements of determinants of LBP at 6 monthly intervals for 3 years during training, and after a 12 month interval there was an additional final follow up.

Results-During training, increased risk of new episodes of LBP was associated with having had LBP at baseline, with part time work, and with a high score on the general health questionnaire (GHQ). A high GHQ score preceded the onset of LBP, in such a way that a high score at the immediately previous follow up increased risk of LBP at the next follow up. 12 Months after training, a history of recurring LBP during training increased the risk of a new episode as did having obtained work as a nurse. A high GHQ score at this follow up was also associated with a concurrently increased risk. Preexisting GHQ score, either at the end of training or at baseline, had no effect on risk of LBP 12 months after training.

Conclusions-Other than a history of LBP, pre-existing psychological distress was the only factor found to have a pre-existing influence on new episodes of LBP. Increased levels of psychological distress (as measured by the GHQ) preceded the occurrence of new episodes of pain by only short intervening periods, implying a role for acute distress in the onset of the disorder. This finding suggests that management of the onset of occupational LBP may be improved by management of psychological distress.

(Occup Environ Med 2000;57:116-120)
\end{abstract}

Keywords: low back pain; nurses; psychological factors

At some time in their lives, most people will experience low back pain (LBP). ${ }^{12}$ It is the most common and the most expensive source of compensated work related injury in modern industrialised countries. ${ }^{34}$ Moreover, both the rate and the degree of disability accruing from LBP are increasing worldwide. ${ }^{356}$

Physical load on the back has commonly been implicated as a risk factor for LBP, and in particular, for work related LBP. Certain occupations and certain work tasks seem to have a higher risk of LBP. ${ }^{7-10}$ However, the evidence for the relation between physical load and musculoskeletal disease has often been weak or contradictory, and it is generally agreed that work related physical load can only partially explain the high prevalence of the problem. ${ }^{11}$ By contrast, association of non-physical factors with LBP has been one of the more robust findings in the scientific literature. Psychological factors have been consistently found to be associated with LBP, with disability arising from LBP, and with treatment outcome. ${ }^{12-16}$ Poor psychosocial work environment and work dissatisfaction have also been found to be associated with LBP and the development of chronicity ${ }^{12} 18$ although contradictory findings have been reported. ${ }^{19}{ }^{20}$

Despite the many publications examining LBP, several key issues concerning occurrence and prognosis remain unanswered. In part this reflects the fact that LBP is a difficult problem to investigate. It has a highly variable natural history and is thought to be multifactorial in origin with a broad range of risk factors involved in its cause and course. To identify critical risk factors or to distinguish between aetiological factors and prognostic factors, study designs which include prospective ascertainment of cases, measurement of multiple and repeated risk factors, and consideration of a comprehensive range of possible determinants are required. The present study sought to consider these issues. A prospective cohort study over 4 years was used to examine the relative contribution of both physical and nonphysical factors to the occurrence of LBP, and to identify key temporal relations between these risk factors and outcome.

\section{Subjects and methods}

The study population consisted of two consecutive first year intakes of a major nursing degree course at a Sydney University. Students entering university were selected as subjects with the aim of recruiting a young group of subjects without history of LBP and without significant previous occupational exposure to physically demanding work, but a group who would ultimately enter an occupation known to be a high risk one for the occurrence of LBP. Two intakes were recruited to provide sufficient subjects who would enter the occupation, given the relatively high attrition from nursing studies. 
All students enrolled and present in the first 2 weeks of the nursing studies course were invited to participate in the study. There were no refusals, resulting in 694 subjects being recruited at baseline. All baseline data were collected during this 2 week period with a self reported questionnaire and four physical measures (height, weight, back flexibility, and lifting strength). The questionnaire obtained information about history of LBP from a questionnaire validated in a cross sectional study reported elsewhere, ${ }^{21}$ and information about various potential risk factors for LBP, including smoking, work history in the past 5 years, recent history of fitness and exercise, current psychological state and recent life events. Cases of LBP at baseline were defined as those subjects who reported having LBP at the time of collection of the questionnaire or in the past 12 months.

At 6 monthly intervals thereafter, the questionnaire was readministered for the remainder of training, giving five follow up occasions over the 3 year training period. A final follow up was undertaken 1 year after graduation from nursing studies, when subjects were expected to have undertaken full time nursing employment. Each follow up questionnaire updated any LBP during the intervening 6 month interval and any major determinants examined at baseline. The follow up questionnaires were essentially the same as that at baseline, with one additional component added. At the end of each year, information was obtained about perceptions of, and satisfaction with, nursing work, as experienced during clinical practice placements while training and during full time employment in the final year of the study.

Standard questionnaires were used for all of the psychological and work related psychosocial variables investigated in the study. The 28 item general health questionnaire (GHQ) was used to evaluate psychological state with total GHQ score dichotomised into low $(\leqslant 5)$ and high $(>5)$ to apply the cut off for distress at clinical levels. ${ }^{22}$ The life events scale adapted for a student population ${ }^{23}$ was used to obtain information about exposure to recent stressful events. Satisfaction with nursing work was examined with the work environment scale, ${ }^{24}$ a scale obtaining perceptions of physical and psychosocial work environment on 10 dimensions (dimensions: involvement, peer cohesion, supervisor support, autonomy, task orientation, work pressure, clarity, control, innovation, and physical comfort). The scale was adapted to obtain a measure of satisfaction on these dimensions as we have reported elsewhere. ${ }^{21}$

Data were not collected on the nature of individual exposure during training. All students rotated through the same range of six clinical placements, two in each year of study, to provide a relatively uniform programmme of learning experience. The placements occurred at a large variety of hospitals associated with the tertiary institution, all in the wider Sydney metropolitan area. The hospitals ranged from large public hospitals to small specialist private hospitals. The order in which placements were undertaken was standard, being based on the part of the course being undertaken by students. The aim of placements was to provide students with a range of hospital experience (within the confines of legal responsibilities of all hospitals with respect to patient care). The contribution of any individual placement was not examined because the type of ward was standard for all students. Hospital differences for the same type of ward were not estimated

ANALYSIS

Two main analytical methods were used. Generalised estimating equations (GEEs) ${ }^{25}$ were used to examine multivariate associations of the full range of demographic (age, sex), physical (body mass, lifting strength, back flexibility), psychosocial (GHQ score, life events score, work satisfaction), health related (smoking, exercise) and work exposure covariates with LBP outcome across the repeated measurements at 6 monthly intervals during training. The GEEs extend logistic regression to account for the correlation between repeated measurements. Data for a person at any time is included whether or not that person has missing data at other times. The technique can use both time dependent and time independent covariates. The GEEs were fitted with proc genmod in SAS using an independent working correlation matrix. To identify key temporal contributions of the covariates, the variables of psychosocial and work exposure were examined at baseline, when concurrent or lagged by one follow up period with reported LBP. To see if the effects were different in those with back pain at baseline the final model was refitted with all variables used as interactions with baseline back pain.

Multivariate logistic regression was used to examine outcome 1 year after completion of training, as this did not involve repeated measurements. Again the full range of predictor baseline and concurrent variables were considered. Also, variables describing patterns of responses during training were examined, including frequency of back pain, frequency of high GHQ score, lagged GHQ score (at the end of training), mean of life events score during training, and mean of satisfaction with nursing work during training.

For all models non-significant variables were removed until the models only contained terms that made a significant contribution to the models.

\section{Results}

The figure summarises the response to follow up across the study. As expected, close to one third of the original cohort dropped out of nursing studies, with most dropping out $(75 \%)$ in the first year. Most subjects who finished training provided complete or nearly complete follow up data during training (55\% complete; $19 \%$ missing one occasion). Twelve months after training, most of those who completed training (and had not withdrawn from the study) provided data. Exhaustive examination of baseline data showed no systematic differences on any of the variables in the study between those subjects who provided complete 


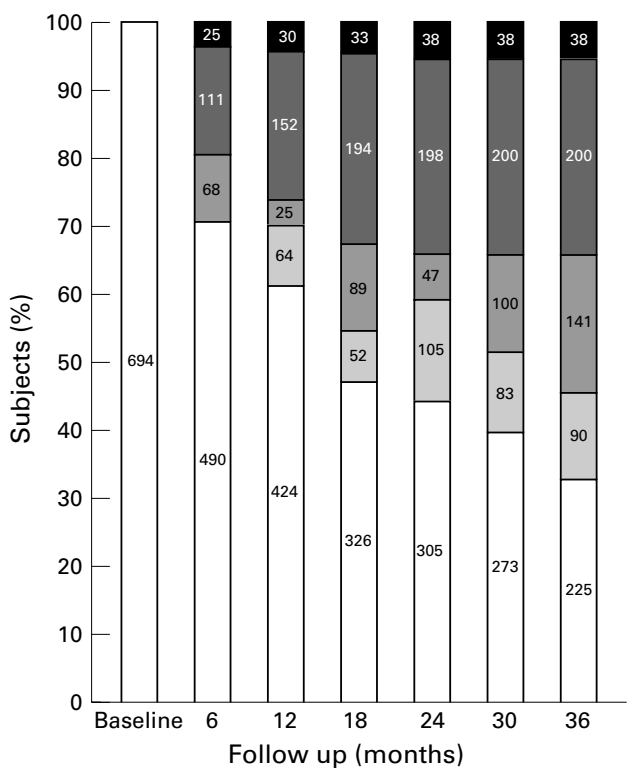

Non-participants (total to this point) Dropouts from nursing (total to that point) Missing this occasion

Responded this occasion, previous missing data (value)

Responded this occasion, complete data to that point

Response rate, attrition, and withdrawals from the study over the follow up period.

data, those who provided partial data, those who withdrew from the study, and those who dropped out of nursing training.

At baseline, the cohort of 694 subjects was, as expected, predominantly a young, female group (table 1). The prevalence of LBP at baseline was reasonably high, with nearly half of the participants being classified as cases. Previous occupational exposure was also relatively common, with nearly half of the subjects reporting having held a job continuously for $>3$ months in the 5 years before the study. Only one third of the cohort were found to be both premorbid and without recent work exposure at baseline. In keeping with the normal population, only a few subjects had a high GHQ at baseline.

Over the follow up period, new episodes of back pain were relatively common. These occurred more often among those who reported being cases at baseline, but also were reported by many new cases (table 1 ). Psychological distress was also commonly reported.

Exposure to work before the end of training was extremely common, with most subjects reporting part time work on at least one follow up occasion (table 1). Given how common exposure to work was, the nature of part time work experience of subjects was examined further. As would be expected, the nature of work undertaken by students was extremely varied. Job titles reported were independently classified as potentially high strain for the low back, or not, by four expert raters (a work physiologist, a human factors psychologist, an ergonomist, and a nurse professional). Reliability between raters was examined: Kendall's coef-
Table 1 Characteristics of the cohort

\begin{tabular}{|c|c|}
\hline Demographic data & $n(\%)$ \\
\hline Age at baseline (mean (SD), y) & $23.7(7.4)$ \\
\hline \multicolumn{2}{|l|}{ Sex: } \\
\hline Women & $590(85)$ \\
\hline Men & $104(15)$ \\
\hline \multicolumn{2}{|l|}{ History of low back pain: } \\
\hline Cases at baseline & $277(40)$ \\
\hline \multicolumn{2}{|l|}{ At baseline: } \\
\hline Current LBP & $86(31)$ \\
\hline Low back pain $\leqslant 12$ months ago & $191(67)$ \\
\hline \multicolumn{2}{|l|}{ Over follow up: } \\
\hline None & $10(4)$ \\
\hline One episode & $12(4)$ \\
\hline Multiple episodes & $136(49)$ \\
\hline Uncertain $\star$ & $119(43)$ \\
\hline Non-cases at baseline & $417(60)$ \\
\hline \multicolumn{2}{|l|}{ At baseline: } \\
\hline Low back pain $>12$ months ago & $69(17)$ \\
\hline Never had low back pain & $348(84)$ \\
\hline \multicolumn{2}{|l|}{ Over follow up: } \\
\hline None & $59(14)$ \\
\hline One episode & $37(9)$ \\
\hline Multiple episodes & $113(27)$ \\
\hline Uncertain ${ }^{\star}$ & $208(50)$ \\
\hline \multicolumn{2}{|l|}{ Work history: } \\
\hline \multicolumn{2}{|l|}{ At baseline: } \\
\hline No full time work & $369(54)$ \\
\hline Full time work $>3$ months & $311(45)$ \\
\hline Full time work $>12$ months & $265(38)$ \\
\hline \multicolumn{2}{|l|}{ Over follow up: } \\
\hline$\geqslant 1$ Part time job & $510(74)$ \\
\hline \multicolumn{2}{|c|}{$\begin{array}{l}\text { Psychological strain, history from the general health } \\
\text { questionnaire: }\end{array}$} \\
\hline High at baseline & $198(29)$ \\
\hline \multicolumn{2}{|l|}{ Over follow up: } \\
\hline No high score & $7(4)$ \\
\hline One high score & $12(6)$ \\
\hline Multiple high scores & $87(44)$ \\
\hline Uncertain $\star^{\star}$ & $92(47)$ \\
\hline Not high at baseline & $494(71)$ \\
\hline \multicolumn{2}{|l|}{ Over follow up: } \\
\hline No high score & $87(18)$ \\
\hline One high score & $35(7)$ \\
\hline Multiple high scores & $131(27)$ \\
\hline Uncertain ${ }^{\star}$ & $241(49)$ \\
\hline \multicolumn{2}{|l|}{ General health at baseline: } \\
\hline BMI (mean (SD)) & $23.5(4.2)$ \\
\hline Currently smoke & $179(26)$ \\
\hline Regular vigorous exercise & $485(70)$ \\
\hline
\end{tabular}

*At least one missing follow up makes unambiguous classification impossible.

ficient of concordance yielded $W=0.49$ with a corresponding $\chi^{2}=124.365, \mathrm{df}=64(\mathrm{p}<0.0001)$ indicating highly significant agreement. Notably, most often, the type of job reported was one that was classified as high strain for the lower back, based on the job title.

Table 2 presents the results of the GEE modelling of the determinants of LBP during training. Greatest increased risk of LBP was associated with being a case at baseline. Risk of LBP was also substantially increased with concurrent part time work and, to a lesser extent, with a concurrent high GHQ. Only very moderate increases in risk were found with higher concurrent recent life events score and greater dissatisfaction with nursing work. The only covariate to show a lagged effect in the model was GHQ score. A high GHQ score at the immediately preceding follow up, independently increased risk of reporting LBP at the next follow up to as great an extent as concurrent psychological status. Using baseline LBP as an interaction variable did not show any difference between those with or without LBP at baseline.

Of those followed up 12 months after completion of training, most reported being employed in nursing work $(83.8 \%)$. Table 3 
Table 2 Determinants of low back pain during training

\begin{tabular}{|c|c|c|c|c|}
\hline & \multicolumn{2}{|c|}{ Unadjusted } & \multicolumn{2}{|c|}{ Adjusted ${ }^{\star}$} \\
\hline & $O R$ & $95 \% C I$ & $O R$ & $95 \% C I$ \\
\hline \multicolumn{5}{|c|}{ General health questionnaire: } \\
\hline Low & 1.0 & Reference & 1.0 & Reference \\
\hline High & 1.95 & 1.58 to 2.41 & 1.36 & 1.09 to 1.71 \\
\hline \multicolumn{5}{|c|}{ General health questionnaire lagged by one period: } \\
\hline Low & 1.0 & Reference & 1.0 & Reference \\
\hline High & 1.87 & 1.50 to 2.33 & 1.42 & 1.13 to 1.78 \\
\hline \multicolumn{5}{|c|}{ History of low back pain during 12 months before the study: } \\
\hline No & 1.0 & Reference & 1.0 & Reference \\
\hline Yes & 3.41 & 2.59 to 4.49 & 3.06 & 2.30 to 4.08 \\
\hline \multicolumn{5}{|l|}{ Working part time: } \\
\hline No & 1.0 & Reference & 1.0 & Reference \\
\hline Yes & 1.69 & 1.24 to 2.30 & 1.65 & 1.19 to 2.28 \\
\hline Life events score & 1.09 & 1.05 to 1.12 & 1.05 & 1.01 to 1.08 \\
\hline Job dissatisfaction score & 1.02 & 1.01 to 1.03 & 1.02 & 1.01 to 1.03 \\
\hline
\end{tabular}

^Adjusted for all the other variables in the model.

Table 3 Determinants of low back pain at 12 months after finishing training

\begin{tabular}{|c|c|c|c|c|}
\hline \multirow[b]{2}{*}{ Variable } & \multicolumn{2}{|c|}{ Unadjusted } & \multicolumn{2}{|c|}{ Adjusted ${ }^{\star}$} \\
\hline & $O R$ & $95 \% C I$ & $O R$ & $95 \% C I$ \\
\hline \multicolumn{5}{|l|}{ Baseline low back pain: } \\
\hline None & 1.0 & Reference & 1.0 & Reference \\
\hline Some & 2.82 & 1.75 to 4.55 & 1.96 & 1.09 to 3.53 \\
\hline \multicolumn{5}{|c|}{ Low back pain during training: } \\
\hline None & 1.0 & Reference & 1.0 & Reference \\
\hline Once & 1.53 & 0.74 to 3.17 & 1.57 & 0.71 to 3.47 \\
\hline Recurrent & 5.92 & 3.30 to 10.61 & 6.36 & 3.18 to 12.73 \\
\hline Uncertain $\dagger$ & 1.90 & 1.00 to 3.60 & 1.89 & 0.66 to 5.40 \\
\hline \multicolumn{5}{|c|}{ Current general health questionnaire: } \\
\hline Low & 1.0 & Reference & 1.0 & Reference \\
\hline High & 2.91 & 1.75 to 4.83 & 2.68 & 1.42 to 5.07 \\
\hline Mean job dissatisfaction & 1.01 & 0.99 to 1.02 & 0.98 & 0.95 to 1.00 \\
\hline \multicolumn{5}{|l|}{ Working as nurse: } \\
\hline Yes & 1.0 & Reference & 1.0 & Reference \\
\hline No & 0.56 & 0.31 to 0.99 & 0.39 & 0.17 to 0.90 \\
\hline
\end{tabular}

*Adjusted for all other variables in the model.

†Missing follow up makes classification impossible.

shows the logistic regression model of determinants of back pain once subjects had entered the workforce, with all tested variables significant. Although being a case of LBP at baseline increased the risk of LBP at this follow up point, more recent history of LBP was much more influential. Recurrent back pain during training was associated with a sixfold increased risk 12 months after training. Increased risk was also associated with having a concurrent high GHQ score at follow up, but not with either GHQ score 12 months earlier (lagged by one follow up) or with baseline GHQ score. Working as a nurse increased the risk to about the same extent as psychological status, whereas satisfaction with nursing work had virtually no effect.

\section{Discussion}

In this comprehensive prospective study, we found that both physical and psychosocial factors were associated with the onset of new episodes of LBP. This provides data based evidence for the current view that a biopsychosocial model is best able to account for the occurrence of LBP. Working part time during nursing training, and working as a nurse once training had been completed, both increased the risk of LBP. Nursing has often been identified as a high risk occupational setting, ${ }^{8}$ and the results of the present study confirm and measure that risk. At the same time, the results of the present study also clearly identified the independent risk associated with psychological distress. Work related psychosocial factors on the other hand, played a less important part. This contrasts with several previous findings. Dissatisfaction has been associated with self reported symptoms, ${ }^{18}$ with reported injury, ${ }^{12}$ and with chronic disability. ${ }^{17}$ Our finding may well reflect that nursing is seen as a vocation, and that those who pursue it as a career are highly committed to the work. In other words, work dissatisfaction as a feature of LBP may be context dependent. ${ }^{20}$ Our finding may also reflect that, in a comprehensive multivariate analysis, the relative contribution of this dimension is small.

Beyond describing the dimensions involved, the present study has, for the first time, identified key temporal relations between determinants and new episodes of LBP. In line with virtually all publications on this disorder, a history of LBP was found to be a robust risk factor for new episodes. However, the present study has shown that recent and recurrent history, rather than simply presence or absence of LBP in the past, is most important. This finding suggests that the progression to chronic recurrence of the disorder may be more rather than less rapid. Future analysis of our data will examine whether other characteristics of chronicity, such as disability and persistence of pain, are also predicted by recent and recurrent history.

Perhaps most notably, the present study identified some important temporal dimensions of psychological risk factors associated with LBP. Although a role for psychological factors has long been postulated, ${ }^{6}$ the nature of that role, cause or effect, has been the subject of considerable debate. The present study has shown that psychological distress, at clinical levels, was associated with increased risk of new episodes of LBP. Moreover, increased levels of psychological distress preceded the occurrence of LBP, but preceded it by only short intervening periods. Baseline levels of distress, and distress 12 months before episodes of LBP were not predictive, whereas distress 6 months before and concurrent with new episodes was associated with an increased risk of LBP. This pattern of findings suggests that reasonably acute psychological factors play an influential part in the early development of LBP. The preexistence of acute psychological distress suggests that LBP, like other sites of pain, may partly reflect the somatic component of clinical levels of acute distress. For some people this process will be expressed as LBP, for others it may be regionalised elsewhere, for instance, headache. ${ }^{26}$

By contrast, the influence of exposure to work related factors did not substantially precede episodes of pain. Work exposure was only associated with LBP when it occurred in the same 6 month period. Work exposure in earlier 6 month periods or before baseline was not predictive of new episodes of LBP. Similarly, employment as a nurse at the end of training was also associated with an increased risk of LBP at the final follow up occasion, but pre-existing history of part time work during 
training was not. This pattern of findings suggests that work related strain early in the course of LBP did not have an accumulated influence, but rather was of relatively short duration before its influence was evident.

These findings have important implications for clinical and preventive medicine. The present study provides epidemiological evidence for the importance of pre-existing acute psychological distress as a risk factor for occupational LBP. Besides recent history of LBP, psychological symptoms were the major preexisting risk factor for new episodes of pain. These findings raise several crucial questions for future research about the relation of early distress to the development of subsequent chronicity, and suggest that management of the onset of occupational LBP may be improved by management of psychological distress. The determinants of patterns of recurrent pain in our cohort are presently being examined.

We are grateful to Ms Sandy Healey for her assistance with baseline data collection and to Ms Samantha Finlay-Brown for management of the data base throughout data collection for the study. The views expressed in this paper are those of the authors and do not necessarily reflect those of the National Occupational Health and Safety Commission.

1 Deyo RA, Cherkin D, Conrad D, et al. Cost, controversy, crisis: low back pain and the health of the public. Annu Rev crisis: low back pain and the he

2 Royal College of General Practitioners. Morbidity statistics from general practice; fourth national survey 1991/2. London HMSO, 1994.

3 Frank JW, Kerr MS, Brooker A-S, et al. Disability resulting from occupational low back pain. Part I: what do we know about primary prevention? A review of the scientific evidence on prevention before disability begins. Spine 1996;21:2908-17.

4 Accident Rehabilitation and Compensation Insurance Corporation. Injury statistics 1998. Wellington: ARCIC, 1998.

5 Frymoyer JW, Cats-Baril WL. An overview of the incidences and costs of low back pain. Orthop Clin North Am 1991;22: 263-71.

6 Waddell G. Low back pain disability: a syndrome of western civilization. Neurosurg Clin N Am 1991;2:719-38.
7 Riihimaki H. Epidemiology and pathogenesis of nonpecific low back pain: what does the epidemiology tell us? Bull Hosp ft Dis 1996;55:197-8.

8 Smedley J, Egger P, Cooper C, et al. Prospective cohort study of predictors of incident low back pain in nurses. $B M \mathcal{F}$ 1997;314:1225-8.

9 Kraus JF, Gardner L, Collins J, et al. Design factors in epidemiologic cohort studies of work-related low back injury or pain. Am F Ind Med 1997;32:153-63.

10 Macfarlane GJ, Thomas E, Papageorgiou AC, et al. Employment and physical work activities as predictors of future low back pain. Spine 1997;22:1143-9.

11 Walsh K, Varnes N, Osmond C, et al. Occupational causes of low-back pain. Scand f Work Environ Health 1989;15:54-

12 Bigos SJ, Battié MC, Spengler DM, et al. A prospective study of work perceptions and psychosocial factors affecting the report of back injury. Spine 1991;16:1-6.

13 Gatchel RJ, Polatin PB, Mayer TG. The dominant role of psychosocial risk factors in the development of chronic low back pain disability. Spine 1995;20:2702-9.

14 Linton SJ. The role of psychological factors in back pain and its remediation. Pain Reviews 1994;1:231-43.

15 Croft PR, Papageorgiou AC, Ferry S, et al. Psychologic distress and low back pain. Evidence from a prospective study in the general population. Spine 1995;20:2731-7.

16 Waxman R, Tennant A, Helliwell P. Community survey of factors associated with consultation for low back pain. $B M F$ 1998;317:1564-7.

17 Williams RA, Pruitt SD, Doctor JN, et al. The contribution of job satisfaction to the transition from acute to chronic low back pain. Arch Phys Med Rehabil 1998;79:366-74.

18 Papageorgiou AC, Macfarlane GJ, Thomas E, et al. Psychosocial factors in the workplace: do they predict new episodes of low back pain? Evidence from the south Manchester back pain study. Spine 1997;22:1137-42.

19 Skovron ML, Mulvihill MN, Sterling RC, et al. Work organization and low back pain in nursing personnel. Ergonomics 1987;30:359-66.

20 Hughes RE, Silverstein BA, Evanoff BA. Risk factors for work-related musculoskeletal disorders in an aluminum smelter. Am f Ind Med 1997;32:66-75.

21 Feyer A-M, Williamson A, Mandryk J, et al. Role of psychosocial risk factors in work-related low-back pain. Scand $\mathcal{F}$ Wocial risk factors in work-related low

22 Goldberg D. The general health questionnaire. Windsor, Berkshire: Nfer-Nelson, 1978.

23 Sarason IG, Johnson JH, Siegel JM. Assessing the impact of life changes: development of the life experiences survey. $\mathcal{F}$ Consult Clin Psychol 1978;46:932-46.

24 Moos RH. Work environment scale. Palo Alto, CA: Consulting Psychologists Press, 1986.

25 Liang K-Y, Zeger SL. Longitudinal data analysis using generalized linear models. Biometrika 1986;73:13-22.

26 Craig TK, Boardman AP, Mills K, et al. The south London somatisation study. I. Longitudinal course and the influence of early life experiences. $\mathrm{Br} \quad \mathcal{F}$ Psychiatry 1993;163:579-88.

\section{Vancouver style}

All manuscripts submitted to Occup Environ Med should conform to the uniform requirements for manuscripts submitted to biomedical journals (known as the Vancouver style.)

Occup Environ Med, together with many other international biomedical journals, has agreed to accept articles prepared in accordance with the Vancouver style. The style (described in full in the $\mathcal{F} A M A[1]$ ) is intended to standardise requirements for authors, and is the same as in this issue.

References should be numbered consecutively in the order in which they are first mentioned in the text by Arabic numerals on the line in square brackets on each occasion the reference is cited (Manson[1] confirmed other reports[2][3][4][5]). In future references to papers submitted to Occup Environ Med should include: the names of all authors if there are three or less or, if there are more, the first three followed by et al; the title of journal articles or book chapters; the titles of journals abbreviated according to the style of Index Medicus; and the first and final page numbers of the article or chapter. Titles not in Index Medicus should be given in full are:

Examples of common forms of references

1 International Committee of Medical Journal Editors. Uniform requirements for manuscripts submitted to Uniform requirements for manuscripts
biomed journals. $\mathcal{F} A M A$ 1993;269:2282-6.

2 Soter NA, Wasserman SI, Austen KF. Cold urticaria: release into the circulation of histmaine and eosinophil chemotactic factor of anaphylaxis during cold challenge. N Engl F Med 1976;294:687-90.

3 Weinstein L, Swartz MN. Pathogenic properties of invading micro-organisms. In: Sodeman WA Jr, Sodeman WA, eds. Pathologic physiology, mechanisms of disease. Philadelphia: W B Saunders, 1974:457-72. 